\title{
STRESS ANALYSIS SIMULATIONS OF WELDED AND BOLTED JOINTS METHOD FOR FULL STEEL AND COMPOSITE-STEEL CHASSIS STRUCTURE OF ELECTRIC LOW FLOOR MEDIUM BUS
}

\author{
Sudirja Sudirja \\ Research Center for Electrical Power and Mechatronics ${ }^{l}$ \\ sudi014@lipi.go.id \\ Abdul Hapid \\ Research Center for Electrical Power and Mechatronics ${ }^{1}$ \\ abdul.hapid@lipi.go.id \\ Amin \\ Research Center for Electrical Power and Mechatronics ${ }^{l}$ \\ amin@lipi.go.id \\ Sunarto Kaleg \\ Research Center for Electrical Power and Mechatronics ${ }^{1}$ \\ sunarto.kaleg@lipi.go.id \\ Alexander Christantho Budiman \\ Research Center for Electrical Power and Mechatronics ${ }^{l}$ \\ alex002@lipi.go.id \\ ${ }^{1}$ Indonesian Institute of Sciences \\ 20 Sangkuriang str., Komplek LIPI Building No. 60, Bandung, West Java, Indonesia, 40135
}

\begin{abstract}
Stress analysis of welded steel-to-steel, bolted steel-to-steel, and bolted composite-steel chassis in an electric low floor medium bus structure is presented in this paper. The analysis was carried out on the condition that is when the bus is full of load in idle/static. This condition reflects the situation of the vehicle in full load with passengers and components, which is important to be analyzed to anticipate the unwanted structural failure of the chassis. Finite Element Method (Harmonic response simulation) is used to investigate the structural behavior of both welded and bolted methods. Several parameters such as 2 Hertz for the maximum frequency, $5000 \mathrm{~kg}$ for the total vehicle weight, and the uniform distribution of load are used for this study to simulate the simplified, real application in the real world. The first comparison is between the welded and bolted steel-to-steel chassis which results in the bolted method has a lower stress value by the difference of $4.3 \mathrm{MPa}$ in the joint section than the welded joint. This means that the bolted joint is more recommended than welded for the use as an electric low floor medium bus and has the potential to be optimized further. In terms of reducing the weight of the chassis structure, then lightweight material (carbon fiber composite) is used to replace the full steel chassis to be a composite-steel chassis. The use of this hybrid material depicts the stress value of $61.5 \mathrm{MPa}$ in the joint area, this value is still far below the limit of carbon fiber that is $3200 \mathrm{MPa}$ makes this bolted composite-steel is considerably safe in full load condition as an electric low floor medium bus structure. Using this hybrid bolted composite-steel chassis structure also reduces the total chassis weight by about $22.7 \%$ compared to the full steel chassis structure, thus one could expect to extend the mileage of electric vehicles by more than $20 \%$.
\end{abstract}

Keywords: Low Floor Medium Bus, Bolted Joint, Welded Joint, Hybrid Chassis Structure, Finite Element Method.

DOI: $10.21303 / 2461-4262.2020 .001516$

\section{Introduction}

The need to be more mobile triggers the increase of vehicle growth in the world. Unfortunately, it causes a lot of environmental problems such as air pollution especially in urban areas $[1,2]$. Emissions from the transportation field are major contributors to air pollution, the top environmental problem risk factor globally [3]. Therefore, reducing fuel consumption is a good approach to solve this problem. 
Many researchers are trying to find alternative energy sources for a vehicle to minimize fuel consumption, especially in public transportation. One of the most popular sources to replace the internal combustion engine (ICE) is by using electrical energy. This kind of source provides cleaner technology and is more environmentally friendly because of its zero-emission [4].

Using public transportation may reduce pollution as it reduces motorized transport [5]. One of the most common problems in public transportation is its limitation for special needs users, these public transportation systems nowadays should allow the disabled, pregnant women, and the elderly to ride without hassle. Thus, low-floor vehicles are designed to meet this demand [6]. But there are still a bunch of problems in electric vehicle structures such as efficiency and safety due to different structural designs compared to ICE. Electric vehicle structure should be able to carry a lot of heavy batteries. However, it also needs to be as light as possible, since the heavier the vehicle, the least efficient it would be [7].

The lightweight construction of automobile components is one of the most important studies in vehicle design [8]. More than $85 \%$ of the fuel energy is consumed by thermal and mechanical inefficiency in the drivetrain, while the remaining $12-15 \%$ is used to overcome the tractive forces that resist forward motion [9]. Of these tractive forces, the weight of the vehicle most significantly affects inertial (acceleration) and rolling resistance forces. On the other hand, it is also reported that a $10 \%$ weight reduction for an electric vehicle could extend the range by $13.7 \%$ [10].

Decreasing the vehicle weight could be achieved through two main approaches, the first is lightweight design of a structure, where vehicle parts are optimized to achieve better performance, and the second is lightweight materials substitution, where lighter materials are used in automobile manufacturing $[11,12]$. Combining a lightweight material with steel material as a chassis part is one possible option in lightweight material substitution on weight reduction efforts. Carbon fiber has recently become one of the most used materials in the automotive field. This type of material is chosen because of its lightweight and has better mechanical properties compared to steel. For the use of a chassis part, material stiffness is the most important point. Thus, carbon fiber material needs to be strengthened by using the right filler.

Lightweight material such as carbon fiber composite has different forms with steel, so it is necessary to find out about the joining method for combining both materials. Several ways have been done by many researchers on combining different materials. Adhesive bonding for compositeto-metal is good because of its small stress concentration. However, this joining method is unable to be disassembled for maintenance or reparation [13]. Meanwhile, the mechanical bolted joint is another method that is frequently used in automotive.

Any structure including bolted and welded joints is subjected to both static and dynamic loads [14]. For example, as a car moves along the road, the chassis experiences the dynamic forces from the road roughness, engine vibration, transmission, etc. Under various dynamic excitations, chassis tend to vibrate under various dynamic excitations [15].

To analyze the stress behavior of two different types of joining methods which are bolted and welded joints, a simulation approach with a harmonic response is used in this study. The condition is set as when the vehicle structure is in full load condition, which is important to spot the stress point to anticipate any structural failure. The first simulation compares the stress of steelto-steel joints with welding and with bolt methods. Secondly, the simulation is used to evaluate the stress from a hybrid bolted joint composite-steel.

A lot of previous research has been done related to the stress analysis in an automobile chassis. Abrams investigated an engine mounting as a structural part of a Formula SAE using the finite element method [16]. Asker, H. K. et al. carried out the stress analysis of truck chassis structure during ramping block using the finite element method (FEM) [17]. FEM is commonly used to analyze the stress and deflection of the chassis structure during the loading condition. The study of chassis behavior using FEM has also been conducted by Nor et al. to improve the design of a low loader chassis. The simulation is done with an investigation towards the critical area of low loader structure that is the contact between the chassis to the axle and also the contact surface between the chassis and gooseneck [18]. The simulation determines the maximum stress value and deflection of the low loader chassis structure. Analytical study about the bolted joint that is used to 
connect different parts has been done by M. H. N. Izham et al. to gain the correlation data between experimental modal analysis (EMA) and finite element method (FEM) [19]. It can be assumed that the different results between both methods can be minimized by optimizing the sensitivity of the analysis. A simulation study is chosen as its flexibility and low cost compared to an experimental that is time-consuming and expensive [20]. But there is still a lack of discussion about stress analysis of chassis structure, especially on low floor medium bus.

Electric low floor medium bus is the object for this study and this paper aims to analyze the stress value and location of bolted joint composite-steel material as a chassis structural by doing some comparison with bolted steel-to-steel and welded steel-to-steel chassis during full load condition on the road using FEM, which is a useful mathematical tool to calculate internal stress and strain analyses of complex structures with geometrical and material nonlinearities.

\section{Methodology}

There are some differences between a low floor and high floor chassis especially on the design and the purpose of each type. In terms of its purpose, the low floor is created to eliminate the boarding problem for special users like seniors and people with disabilities. On the constructions, the low floor is designed with a different height between the rear and the middle part of the chassis while the high floor looks more level as shown in Fig. 1 to accommodate the different height of the low floor chassis, a joint method is used.

Investigating the joint performance on a chassis structure under full load conditions is important to identify the potential structural failure. The frequency of chassis structure on the road is set 2.0 hertz as the highest value since the vehicle body modal response has two natural damped frequencies around 1.0-2.0 Hertz [22]. The total weight of a medium bus is usually around $5000 \mathrm{~kg}$ based on Federal Highway Administration (FHWA) vehicle classes. The simulation is extended further by using various safety factors 1.5 to 4 . The design of welded composite-steel and bolted steel-to-steel chassis used in this study are shown in Fig. 2.

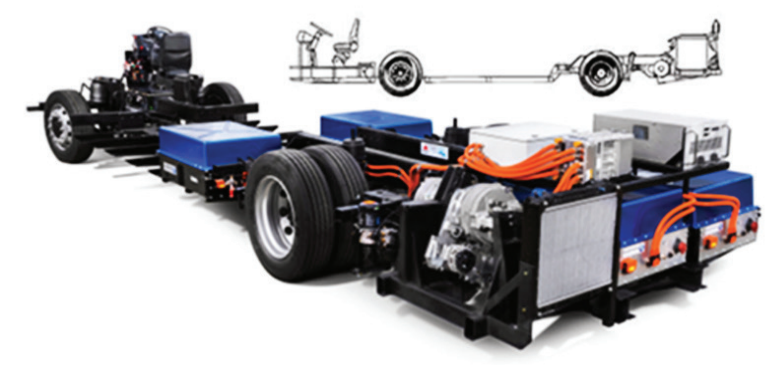

$a$

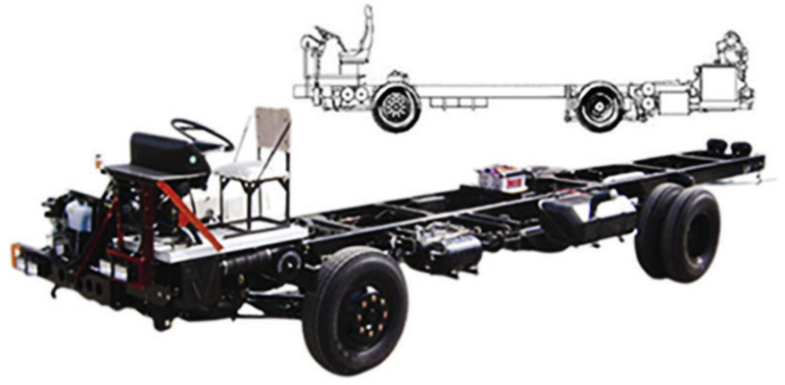

$b$

Fig. 1. Types of bus chassis [21]: $a$ - Low floor chassis; $b$ - High floor chassis

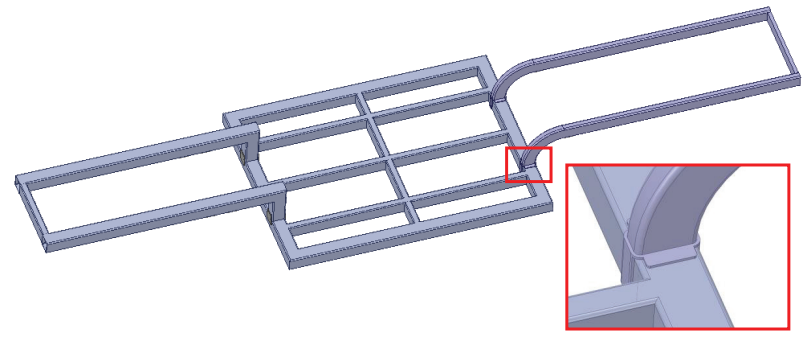

$a$

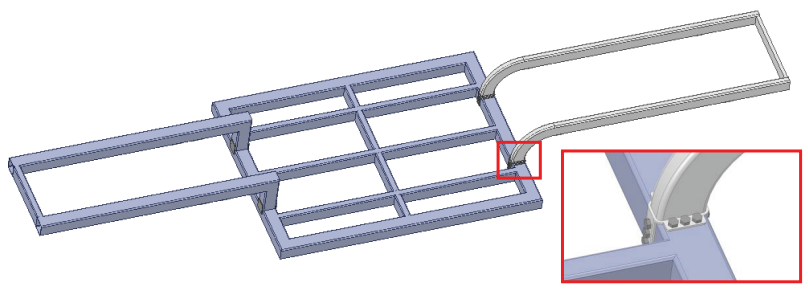

$b$

Fig. 2. Low floor medium bus structures: $a$-welded steel-to-steel chassis; $b$ - bolted composite-steel chassis

The main consideration that any vehicle model must satisfy is to forecast the modal basis of the vehicle [23]. ANSYS Workbench Space Claim software is used for 3D modeling of the hybrid 
composite-steel chassis for electric low floor medium bus. The use of ANSYS can provide an optimum shape design [24]. This study is carried out based on the following assumptions:

- the maximum frequency of the simulation is 2 Hertz;

- the total load is $50 \mathrm{kN}$;

- the load is constant and distributed over the contact surface on the chassis structure.

The stress simulation of hybrid composite-steel part for a chassis structure is the main interest of this paper. The mechanical properties used in this study were adapted from our previous investigation on the characterization of carbon fiber with microspheres filler [25]. It is known that the addition of such filler could add rigidity into the carbon fiber by a maximum strain of $1.17 \%$ without any significant weight addition.

The mechanical properties of composite carbon fiber and steel are shown in Table 1.

Table 1

Material properties of carbon fiber and structural steel

\begin{tabular}{lcc}
\hline & Carbon fiber & Structural steel \\
\hline Modulus Elasticity, $E(\mathrm{GPa})$ & 9.35 & 210 \\
Density $\left(\mathrm{kg} / \mathrm{m}^{3}\right)$ & 1480 & 7850 \\
Poisson Ratio & 0.3 & 0.3 \\
Tensile Strength $(\mathrm{GPa})$ & 0.1 & 0.5
\end{tabular}

Eight fixed areas that represent the front and rear suspension points are shown in Fig. 3. The dimension of each suspension point is based on the real condition of the common ICE-based medium bus in Indonesia.
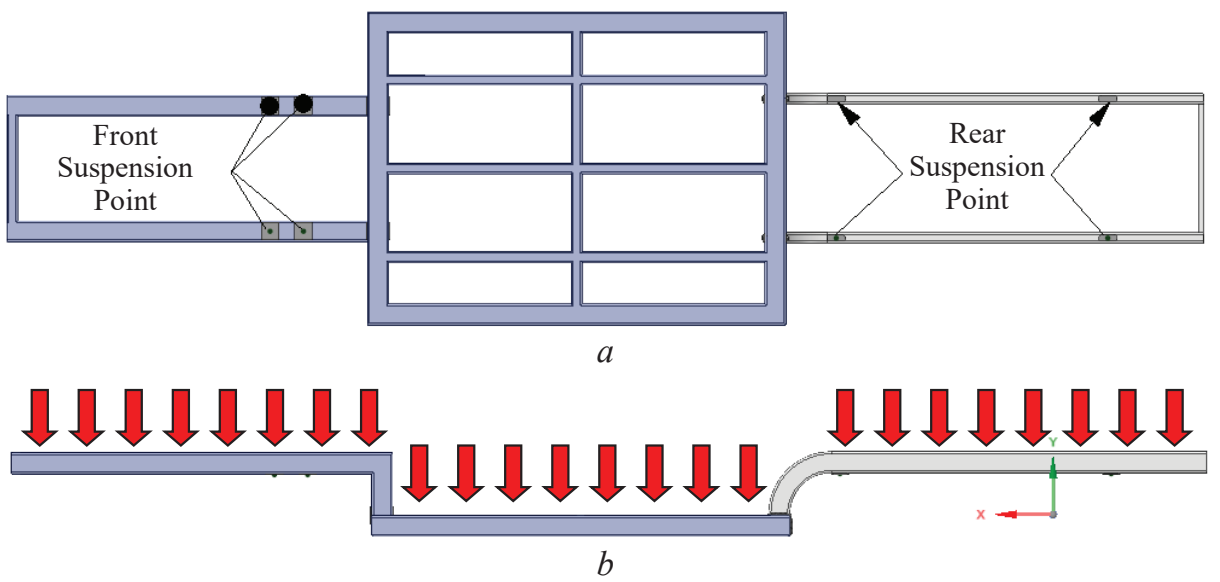

Fig. 3. Boundary conditions:

$a$ - Front and rear suspension point of both welded full steel and bolted composite-steel chassis structure; $b$ - contact surface for loading condition of chassis structure simulation

The load for this simulation is $50 \mathrm{kN}$ distributed on the contact surface of the chassis structure in the $-Y$ direction as seen in Fig. 3. This load displays the total load of the medium bus $(5000 \mathrm{~kg})$ multiplied by the safety factor 1.5 to 4 .

Fig. 4 shows the mesh of this chassis structure. An adaptive meshing method is chosen for this chassis design to cover all the complex geometry, especially at the bolted connection area.

This kind of meshing method can provide clear and symmetry mesh which is important in simulation works. Fig. 3 shows the meshing in the outer area of this clamped part of the joint that is covered by all geometries such as bolts and nuts. As seen in Fig. 4, the hole for all bolts is also important to confirm its mesh condition to make sure all spaces are covered. 

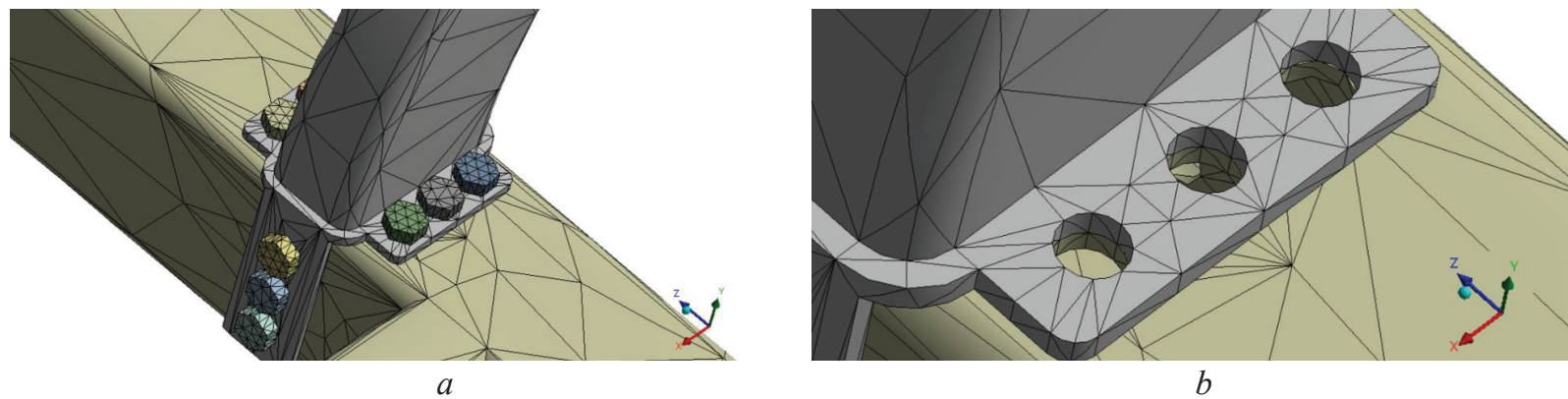

Fig. 4. The Meshing of low floor electric medium bus with hybrid composite-steel chassis structure: $a$-bolted joint section; $b$ - bolted contact surface

\section{Results}

\section{1. Welded and Bolted Full Steel Chassis}

Fig. 5, 6 show the stress distribution under the full load condition of welded and bolted steel to steel chassis structure. As presented in Fig. 5, 6, the maximum stress value of this chassis structure is in the rear suspension point. The maximum stress of welded full steel chassis is $185.9 \mathrm{MPa}$ as shown in Fig. 5 and the maximum stress of bolted full steel structure that is $196.4 \mathrm{MPa}$ as seen in Fig. 6. It can be concluded that stress is not concentrated in the joint area. Previously, Nor et al. carried out the stress simulation on the low loader chassis, and from the simulation, it shows the maximum stress point appears on the contact surface between the front beam and gooseneck part [18]. This result shows a good agreement that the stress point tends to appear in the connection area of a structure.

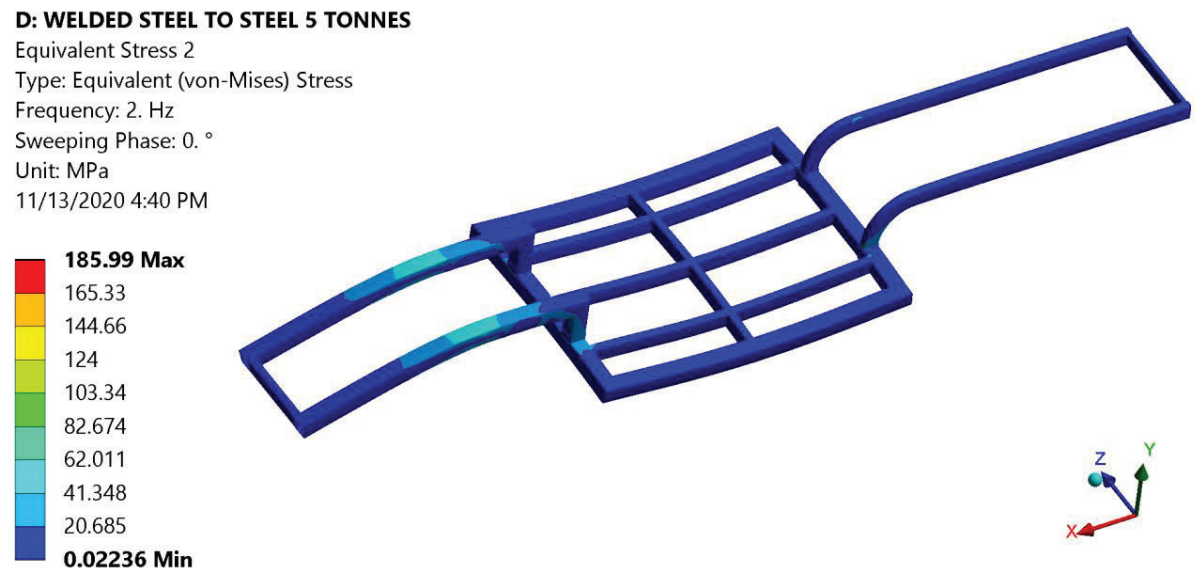

Fig. 5. Maximum stress location of welded steel-to-steel simulation

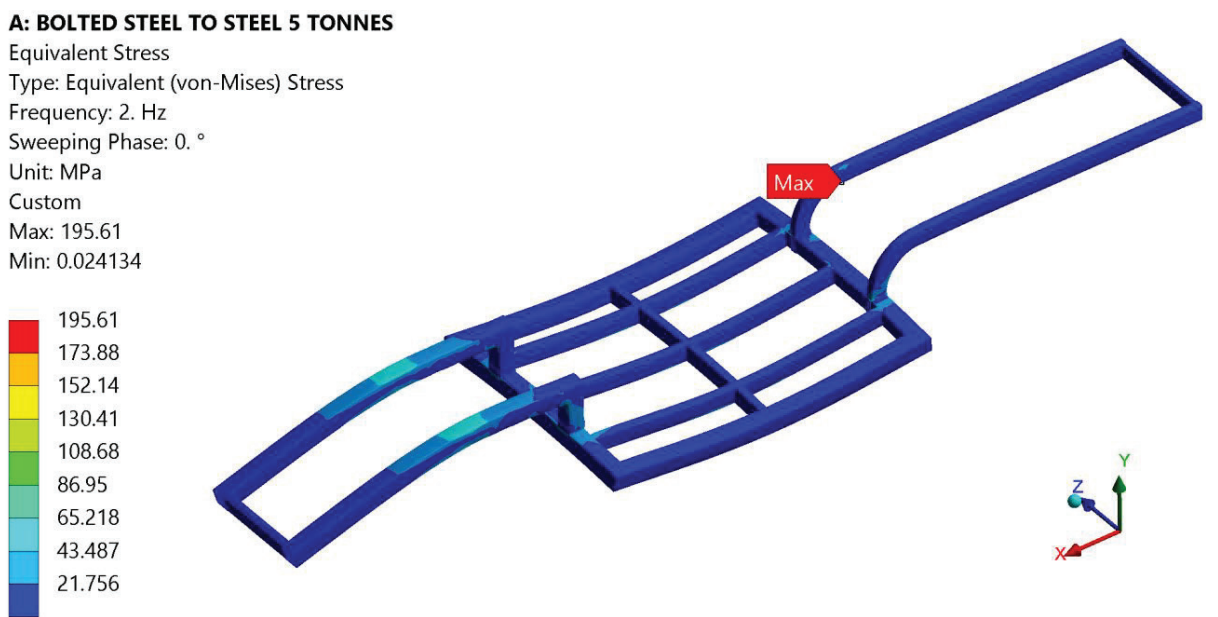

Fig. 6. Maximum stress location of bolted steel-to-steel simulation 


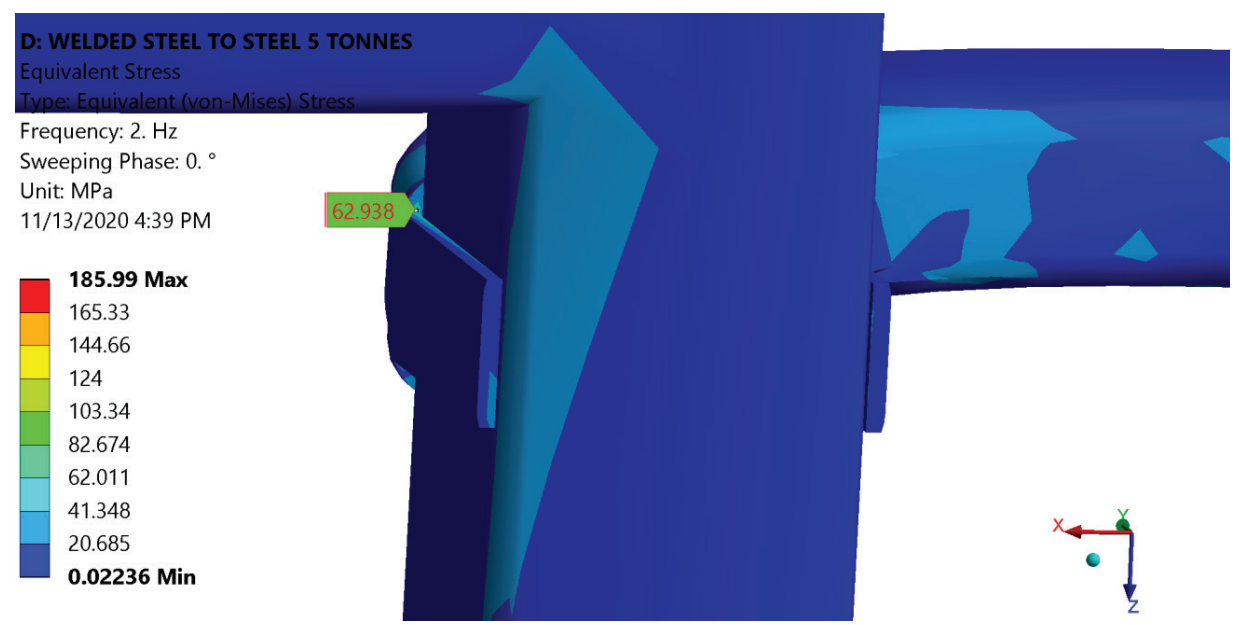

Fig. 7. Probed on the highest stress value in welded steel-to-steel chassis structure

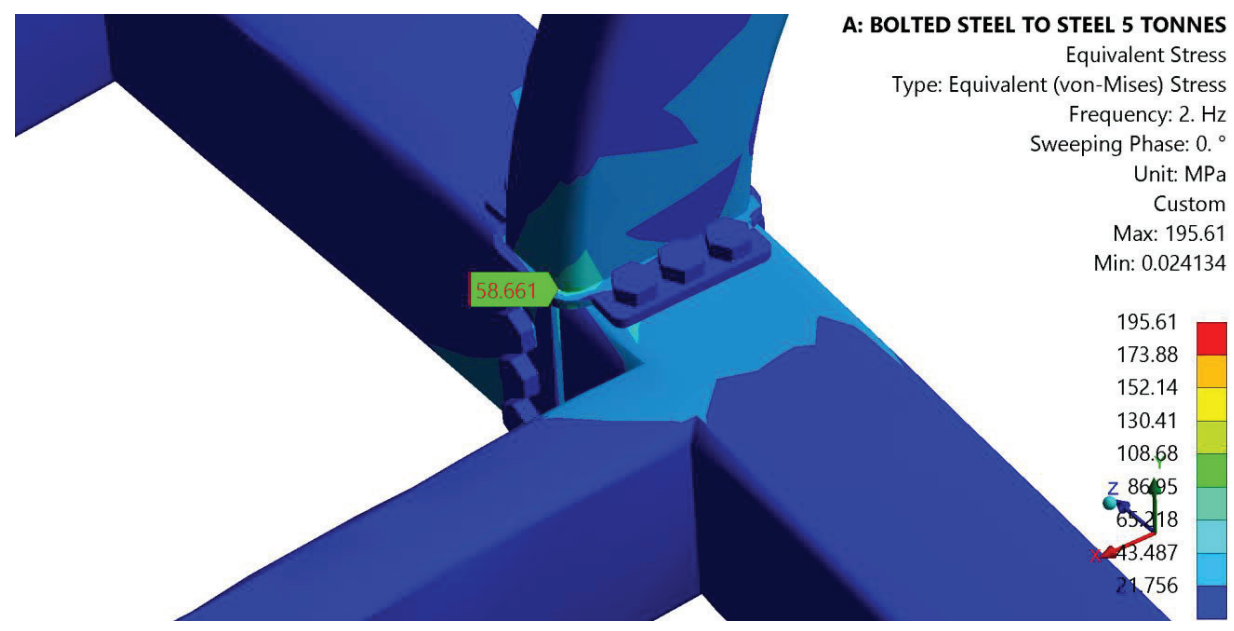

Fig. 8. Probed on the highest stress value in the bolted steel-to-steel chassis structure

The result shows that the bolted joint section is considerably safe for full load conditions since the maximum stress value does not exceed the ultimate stress of steel material which is $420 \mathrm{MPa}$.

Probing is one of the ways that can be used for measuring the specific value in a component [26]. As presented in Fig. 7, the probed stress value in welded full steel chassis is $62.9 \mathrm{MPa}$ while the bolted steel to steel shows a lower stress value, which is 58.6 MPa as seen in Fig. 8. From these simulation results, it can be confirmed that the bolted joint method has a smaller stress value in the connection area which means that this method is more preferred than welded for as the application in an electric low floor medium bus.

According to the results, due to its lower stress value in full load condition, the bolted joint method has a potential for weight optimization by utilizing its advantages to be dismantled by replacing the rear steel part of the structure with a lightweight chassis structure in terms of achieving better efficiency for an electric vehicle.

\section{2. Bolted Steel to Steel and Bolted Composite-Steel Chassis}

In the second simulation study, carbon fiber is used as a composite material because of its high maximum stress that is $3200 \mathrm{MPa}$. A bolted composite-steel is then compared to the bolted full steel chassis to find out the stress value and location for the possibility to be used as a safe electric low floor medium bus structure. Similar simulation parameters as the bolted and welded comparison in the previous section are also used. As shown in Fig. 9, the maximum stress value of bolted composite-steel chassis appears in the rear suspension point and the value is $203.5 \mathrm{MPa}$ which is still far below the limit of carbon fiber stress. 
The probed stress value of bolted composite-steel chassis structure shows the acceptable value that is $61.5 \mathrm{MPa}$. Therefore, the maximum stress value on this hybrid chassis structure does not occur in the bolted joint area as presented in Fig. 10, which means that the stress value does not concentrate on the joint section as well as the bolted steel-to-steel chassis.

This simulation is also briefly expanded to cornering and braking situations. The results show that the maximum stress appears roughly at the same location as the full load condition. The maximum stress under the cornering and braking conditions are 54.2 MPa and $51 \mathrm{MPa}$, respectively. Because both values are lower than under the full load condition, it could be concluded that both dynamic conditions could be generally represented by this full load condition.

Different safety factors are used in this simulation as presented in Table 2. The maximum stress of probed von Mises bolted composite-steel using the highest safety factor is $246.3 \mathrm{MPa}$, which is still lower than the maximum stress limit of the composite that is $3200 \mathrm{MPa}$. This means that the stress value of the bolted composite-steel joint method is acceptable for full load conditions since it does not exceed the maximum strength of the carbon fiber composite.

The comparison between simulation study and analytical calculation in terms of determining the average stress on the contact area of the bolted part is shown in Table 2. For theoretical stress calculation let's use the formula:

$$
A p t=\pi d^{0} t p
$$

where Apt is the surface area of contact, $d^{0}$ is the diameter of the surface area of contact, $t p$ is the thickness of the part being considered. This formula is used to identify the area that experiences stress.

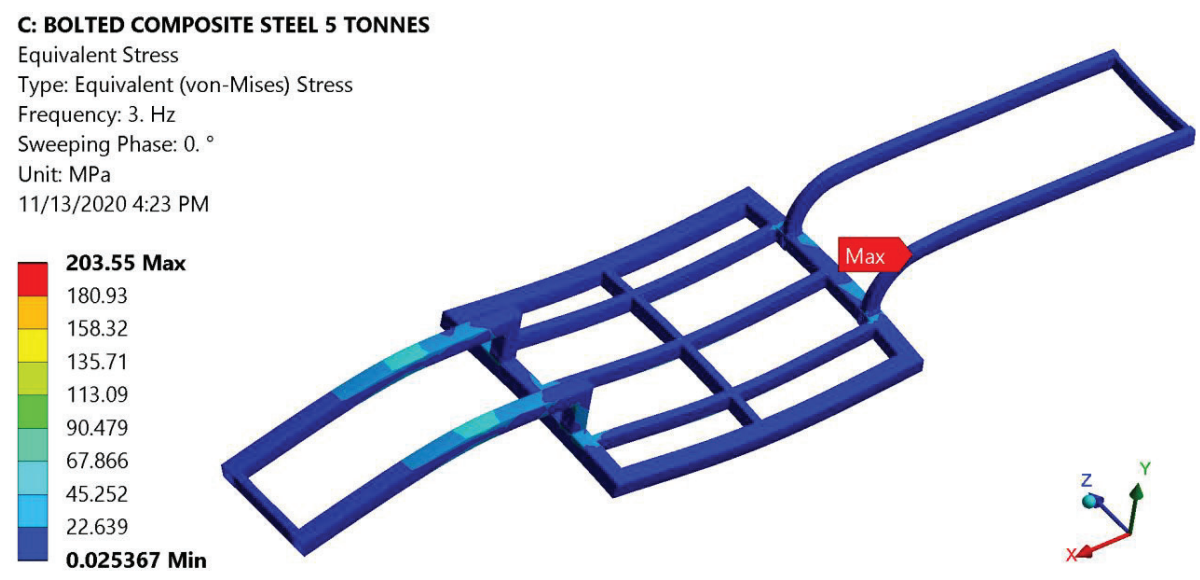

Fig. 9. Maximum stress location of bolted composite-steel simulation

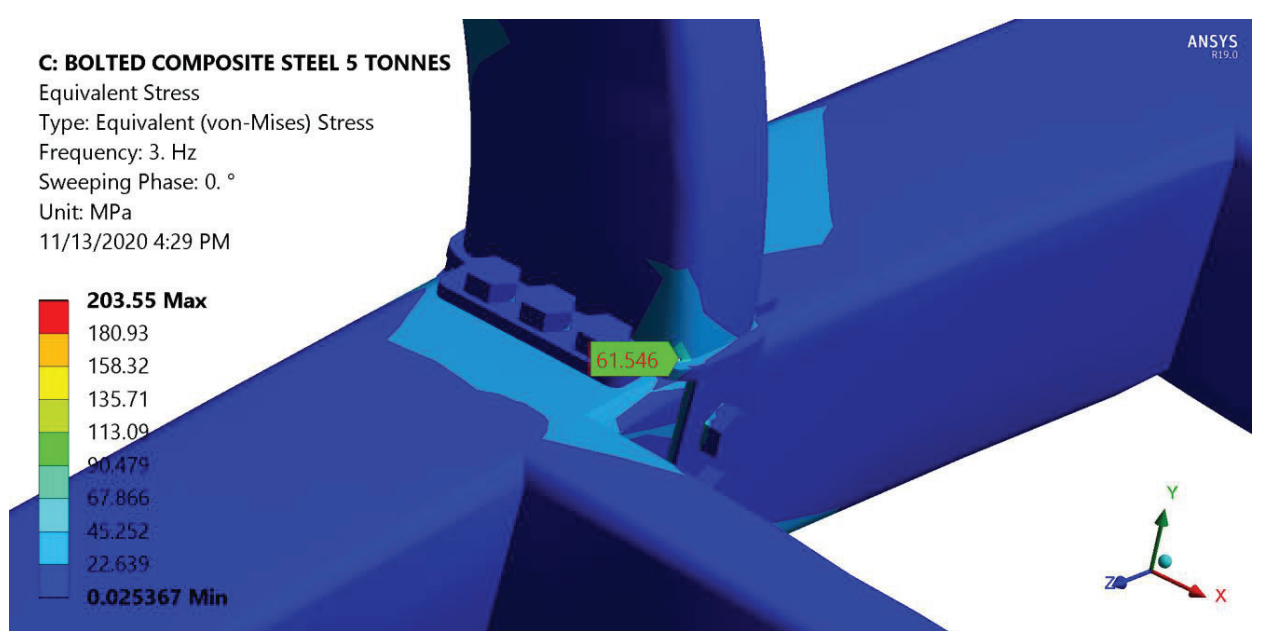

Fig. 10. Probed on the highest stress value in the bolted composite-steel chassis structure 
After that, the stress of the clamped area can be determined by using this formula:

$$
T p t=(F t \cdot a p p) / A p t
$$

where Tpt is the stress of the clamped part, Ft app is a total force that is applied to the structure. Assuming the different directions of a force on the contact surface and specific setting of fixed support in this simulation leads to the different results between the theoretical and simulation.

Table 2

Simulation results with various safety factor

\begin{tabular}{|c|c|c|c|c|c|}
\hline \multirow{2}{*}{ Safety factor } & \multirow{2}{*}{ Load (kg) } & \multirow{2}{*}{$\begin{array}{l}\text { Probe von Mises } \\
\text { (MPa) }\end{array}$} & \multicolumn{2}{|c|}{ Stress average on contact area (MPa) } & \multirow{2}{*}{ Max. deformation } \\
\hline & & & Simulation & Theoretical & \\
\hline 1 & 5000 & 61.5 & 12.07 & 12.2 & 2.82 \\
\hline 1.5 & 7500 & 93 & 18.1 & 18.4 & 4.23 \\
\hline 2 & 10000 & 124.4 & 24.15 & 24.6 & 5.64 \\
\hline 2.5 & 12500 & 153 & 30.17 & 30.7 & 7.05 \\
\hline 3 & 15000 & 185.8 & 36.2 & 36.8 & 8.46 \\
\hline 3.5 & 17500 & 217 & 42.2 & 42.9 & 9.87 \\
\hline 4 & 20000 & 246.3 & 48.3 & 49.1 & 11.28 \\
\hline
\end{tabular}

\section{Discussion of results}

The simulation shows the bolted joint has a lower stress value in the joint area than the other one which means this joining method is considered safe to be used as a low floor chassis. The material substitution from steel-to-steel into composite-steel has good potential in terms of weight reduction. The full steel chassis weight is $233.7 \mathrm{~kg}$ while the composite-steel is only $188.5 \mathrm{~kg}$, which is lower by $22.7 \%$. This weight reduction could lead to more mileage covered by the bus every charging cycle (EV) or every liter of fuel (conventional ICE bus) than the existing full steel chassis, hence increasing its efficiency and reducing its side effect to the environment in the forms of air pollution since $10 \%$ of weight reduction can improve the EV range by $13.7 \%$ [10]. From this statement, one may expect to have the mileage extension of the electric vehicle for more than $20 \%$ just by applying this material substitution.

This research is limited to the analysis of the stress value of bolted and welded joints on specific low floor chassis for an electric medium bus. The stress analysis is carried out by a simulation approach using harmonic response tools in the Finite Element Method. The disadvantage of using bolts in the connection method is the possibility of damage on or caused by the bolt itself which results in structural failure, therefore the quality of the bolt components must be considered and treated carefully. Unlike the bolted method, adhesive bonding also provides a low stress value due to its small concentration. In the future, this method could become another option to be used as a joining method especially for automotive chassis considering it does not require additional components such as bolts and other fastener items that increase the structural weight.

Similar to any other computational works, the quantitative results presented in this manuscript would still require further validations by means of industrial testing in the real world condition, where some assumptions used in this study might not be practically applied. For example, in certain critical road or vehicle conditions that may cause the natural frequencies beyond the normal range as assumed in this work or when the load distribution is not perfectly uniform. Such examples create more complex conditions such that there is a possibility that the real world condition would slightly differ. Meanwhile, this simulation work could also be extended in the future to evaluate the hybrid carbon fiber composite to become a beam profile with specific shapes. This would be beneficial to extend the evaluation not only in chassis structure but also to other parts of the vehicles. 


\section{Conclusion}

The stress on the chassis joint method using steel-to-steel and composite-steel materials is numerically analyzed in this manuscript. Comparing the welded and bolted steel-to-steel chassis method shows that the bolted method has a lower stress value on the joining section which is considered safe in its use as an electric low floor medium bus. Integrating lightweight materials such as hybrid composite-steel into a chassis structure is a good approach to reduce vehicle weight that can lead to better efficiency, especially for an electric car with its heavy components. The FEM-based simulation displays a good result for the composite-steel in terms of stress value that is $61.5 \mathrm{MPa}$ in the joining section and $813.7 \mathrm{MPa}$ for the whole chassis structure under full load condition. For further comparison, the simulation also shows that the welded full steel and the bolted full steel chassis has a stress value of $62.9 \mathrm{MPa}$ and $58.6 \mathrm{MPa}$, respectively. Following these results, it can be concluded that this hybrid composite-steel chassis does not have significant probed stress differences than the other two methods hence it could still be considered safe to be used for a medium bus chassis. The use of this hybrid structure also can reduce the weight for chassis by $22.7 \%$.

\section{References}

[1] Shabbir, R., Ahmad, S. S. (2010). Monitoring urban transport air pollution and energy demand in Rawalpindi and Islamabad using leap model. Energy, 35 (5), 2323-2332. doi: https://doi.org/10.1016/j.energy.2010.02.025

[2] Chen, W.-M., Lee, T., Lee, P. V.-S., Lee, J. W., Lee, S.-J. (2010). Effects of internal stress concentrations in plantar soft-tissue - A preliminary three-dimensional finite element analysis. Medical Engineering \& Physics, 32 (4), 324-331. doi: https:// doi.org/10.1016/j.medengphy.2010.01.001

[3] Anenberg, S. C., Miller, J., Henze, D. K., Minjares, R., Achakulwisut, P. (2019). The global burden of transportation tailpipe emissions on air pollution-related mortality in 2010 and 2015. Environmental Research Letters, 14 (9), 094012. doi: https:// doi.org/10.1088/1748-9326/ab35fc

[4] Ferrero, E., Alessandrini, S., Balanzino, A. (2016). Impact of the electric vehicles on the air pollution from a highway. Applied Energy, 169, 450-459. doi: https://doi.org/10.1016/j.apenergy.2016.01.098

[5] Kwan, S. C., Hashim, J. H. (2016). A review on co-benefits of mass public transportation in climate change mitigation. Sustainable Cities and Society, 22, 11-18. doi: https://doi.org/10.1016/j.scs.2016.01.004

[6] T Kalina, T., Heller, P., Chval, Z., Sedláček, F., Kř́ižek, M., Bartoň, L. (2018). Numerical Simulation and Experimental Testing of Two-axle Chassis of Low-floor Trams. Manufacturing Technology, 18 (2), 248-254. doi: https://doi.org/10.21062/ ujep/86.2018/a/1213-2489/mt/18/2/248

[7] Lyu, M.-Y., Choi, T. G. (2015). Research trends in polymer materials for use in lightweight vehicles. International Journal of Precision Engineering and Manufacturing, 16 (1), 213-220. doi: https://doi.org/10.1007/s12541-015-0029-x

[8] Güler, T., Demirci, E., Yıldız, A. R., Yavuz, U. (2018). Lightweight design of an automobile hinge component using glass fiber polyamide composites. Materials Testing, 60 (3), 306-310. doi: https://doi.org/10.3139/120.111152

[9] Cheah, L. W. (2010). Cars on a diet: the material and energy impacts of passenger vehicle weight reduction in the U.S. Massachusetts Institute of Technology.

[10] Joost, W. J. (2012). Reducing Vehicle Weight and Improving U.S. Energy Efficiency Using Integrated Computational Materials Engineering. JOM, 64 (9), 1032-1038. doi: https://doi.org/10.1007/s11837-012-0424-Z

[11] Witik, R. A., Payet, J., Michaud, V., Ludwig, C., Månson, J.-A. E. (2011). Assessing the life cycle costs and environmental performance of lightweight materials in automobile applications. Composites Part A: Applied Science and Manufacturing, 42 (11), 1694-1709. doi: https://doi.org/10.1016/j.compositesa.2011.07.024

[12] Sudirja, Adhitya, M. (2018). Flying-cars body manufacturing using spraying elastic waterproof and water-absorbing frame fabric method. AIP Conference Proceedings. doi: https://doi.org/10.1063/1.5051976

[13] Croccolo, D., De Agostinis, M., Vincenzi, N. (2011). Structural Analysis of an Articulated Urban Bus Chassis via FEM: a Methodology Applied to a Case Study. Strojniški Vestnik - Journal of Mechanical Engineering, 57 (11), 799-809. doi: https:// doi.org/10.5545/sv-jme.2011.077

[14] Ouyang, H. (2011). Moving-load dynamic problems: A tutorial (with a brief overview). Mechanical Systems and Signal Processing, 25 (6), 2039-2060. doi: https://doi.org/10.1016/j.ymssp.2010.12.010

[15] Fui, T. H., Rahman, R. A. (2007). Statics and dynamics structural analysis of a 4.5 ton truck chassis. Jurnal Mekanikal, 24, 56-67.

[16] Abrams, R. (2008). Formula sae race car analysis: simulation \& testing of the engine as a structural member. In FISITA 2008 World Automotive Congress. Munich. 
[17] Asker, H. K., Dawood, T. S., Said, A. F. (2012). Stress Analysis of standard Truck Chassis during ramping on Block using Finite Element Method. ARPN Journal of Engineering and Applied Sciences, 7 (6), 641-648.

[18] Nor, M. A. M., Rashid, H., Mahyuddin, W. M. F. W., Azlan, M. A. M., Mahmud, J. (2012). Stress Analysis of a Low Loader Chassis. Procedia Engineering, 41, 995-1001. doi: https://doi.org/10.1016/j.proeng.2012.07.274

[19] Izham, M. H. N., Abdullah, N. A. Z., Zahari, S. N., Sani, M. S. M. (2016). Structural dynamic investigation of frame structure with bolted joints. MATEC Web of Conferences, 90, 01043. doi: https://doi.org/10.1051/matecconf/20179001043

[20] Baykasoglu, C., Sunbuloglu, E., Bozdag, S., Aruk, F., Toprak, T., Mugan, A. (2012). Numerical static and dynamic stress analysis on railway passenger and freight car models. International Iron \& Steel Symposium. Karabük, 579-586.

[21] Raveendran, A., Sridhara, S. N., Rakesh, D., Shankapal, S. R. (2009). Exterior Styling of an Intercity Transport Bus for Improved Aerodynamic Performance. SAE Technical Paper Series. doi: https://doi.org/10.4271/2009-28-0060

[22] Spinola Barbosa, R. (2012). Vehicle Vibration Response Subjected to Longwave Measured Pavement Irregularity. Journal of Mechanical Engineering and Automation, 2 (2), 17-24. doi: https://doi.org/10.5923/j.jmea.20120202.04

[23] Liebregts, R. (2014). Concept modelling and simulation in truck chassis design. PROCEEDINGS OF ISMA2014 INCLUDING USD2014, 1665-1676.

[24] Beňo, P., Kozak, D., Konjatić, P. (2014). Optimization of thin-walled constructions in CAE system ANSYS. Tehnicki Vjesnik, 21 (5), 1051-1055.

[25] Sudirja, Hapid, A., Kaleg, S., Budiman, A. C., Amin (2019). The Crumple Zone Quality Enhancement of Electric Cars Bumper Fascia using a Carbon Fiber Reinforced Vinyl Ester - Microsphere Composites. 2019 International Conference on Sustainable Energy Engineering and Application (ICSEEA). doi: https://doi.org/10.1109/icseea47812.2019.8938633

[26] Li, R.-J., Xiang, M., He, Y.-X., Fan, K.-C., Cheng, Z.-Y., Huang, Q.-X., Zhou, B. (2016). Development of a High-Precision Touch-Trigger Probe Using a Single Sensor. Applied Sciences, 6 (3), 86. doi: https://doi.org/10.3390/app6030086

Received date 02.10.2020

Accepted date 10.11.2020

Published date 30.11.2020
(C) The Author(s) 2020

This is an open access article under the CC BY license (http://creativecommons.org/licenses/by/4.0). 